\title{
Generatiivinen vs. konnektionistinen paradigma muuntelun tutkimuksessa
}

Kansanmusiikin yksi keskeisiä piirteitä on muuntelu. Tässä yhteydessä muuntelulla tarkoitan ilmiötä, jossa "sama sävelmä" lauletaan tai soitetaan eri tavoin eri esityskerroilla. Mitkä toisinnoista pitäisi määritellä "saman sävelmän" toisinnoiksi on monella tavoin vaikea kysymys. Vastaus riippuu mm. siitä, tarkastellaanko asiaa musiikintutkijan vai kansanmuusikon näkökulmasta. Musiikintutkija voi löytää helpostikin toisintojen takaa yhteisen alkuperän, jota kuulija ei ilman erityisponnisteluja kuule.

Muuntelua ja siihen liittyvää kysymystä sävelmätoisinnoista on tutkittu runsaasti. Tämän vuosisadan alkupuolella muuntelua ja toisintoja tutkittiin vertailevan musiikkitieteen menetelmin. 1950-luvulla kielitieteilijöiden piirissä kiinnostuttiin generatiivisen kieliopin mahdollisuuksista ja pian myös musiikintutkijat pyrkivät soveltamaan generatiivista teoriaa omiin tutkimuskohteisiinsa ${ }^{1}$. Ruotsalaisten tutkijoiden Johan Sundbergin ja Björn Lindblomin tavoitteena oli formuloida generatiivinen kielioppi, joka kykenisi tuottamaan Alice Tegnérin tyyliä noudattavia lastenlauluja. Myöhemmin Johan Sundberg ja Björn Lindblom sovelsivat samaa metodia sävelmätoisintoja koskevassa tutkimuksessaan $^{2}$. Tämä oli teoreettisesti mielenkiintoinen yritys lähes- 
tyä uudesta näkökulmasta sävelmätoisintoja koskevaa kysymystä. Tutkimus antoi samalla uuden teoreettisen mallin toisintoja ja muuntelua koskeville tutkimuksille. Tutkijoiden tarkoitus oli pyrkiä ymmärtämään syvemmin sävelmätoisintoja ja kehittämään aikaisempaa parempi malli, joka voisi auttaa ymmärtämään ja selittämään toisintojen syntyä ja muuntelua. Keskeinen metodinen ajatus oli testata mallia simulaation avulla. Mikäli laadittu generatiivinen kielioppi tuottaisi uusia sävelmätoisintoja, joita kompetentti kuulija pitäisi tyylinmukaisina, pidettäisiin mallia onnistuneena. Sen sijaan, jos generatiivinen kielioppi tuottaisi epätyydyttäviä toisintoja, sitä korjattaisiin niin kauan kunnes se tuottaisi tyydyttäviä toisintoja.

Generatiiviseen kielioppiin liittyy monia ongelmia, jotka tulevat musiikin tutkimuksessa korostuneesti esille. On ilmennyt, että on mahdollista laatia useita kielioppeja, jotka tuottavat saman lopputuloksen. Mikä on silloin peruste, jolla valitaan eri kielioppien välillä? Havainnollistan kysymystä liitteessä 1 olevan kuvan avulla. Kuvassa on näkyvissä kaksi fraktaalia, jotka voitaisiin "selittää" laatimalla kielioppi ${ }^{3}$. Tätä - todennäköisesti monimutkaiseksi muodostuvaa - kielioppia käyttäen voisimme tuottaa uusia fraktaaleja. Ongelmana on, että tiedämme molempien fraktaalien perustuvan yksinkertaiseen matemaattiseen kaavaan $z i+1=z i 2+c$. Fraktaalien selittämiseen emme näin ollen tarvitse kielioppia.

Voimme laatia kiinnostavia toisintojen syntyä koskevia hypoteeseja, mutta jos mallin epistemologinen perusta on heikko, ei edes se riitä, että hypoteeseja testaamaan laadittu kielioppi tuottaa tyydyttäviä tuloksia (esim. uusia toisintoja). Mallin on oltava yhtä hyvin psykologisesti kuin myös neurofysiologisesti uskottava ${ }^{4}$. Konnektionismi ei pyri selittämään ilmiöitä vain tutkimalla ilmiasua (fraktaaleita), vaan pyrkii löytämään ilmiasun takana olevan mekanismin (matemaattisen kaavan). Konnektionismi lähtee ajatuksesta, että tietokoneen avulla on mahdollista simuloida aivojen neurofysiologista rakennetta käyttäen nk. keinotekoisia hermosoluja eli neuroneita. Tietokone antaa mahdollisuuden simuloida aivojen toimintaa, joskin hyvin alkeellisella tasolla.

Generatiivinen lähestymistapa ei ota huomioon oppimisprosessia, jolla kuitenkin on ilmeisesti keskeinen merkitys toisintojen synnyssä. Jos tavoitteenamme on ymmärtää ja selittää toisintojen syntyä ja muuntelua, oppiminen pitäisi olla kiinteä osa mallia. Generatiiviseen paradigmaan liittyy myös kieliopin laadintaa koskeva ongelma. Kyetäksemme laatimaan kieliopin, meidän on kuvattava ilmiö symboli- 
sessa muodossa ja laadittava sääntöjärjestelmä. Musiikillisten ilmiöitten kuvaaminen symbolisella tasolla ei kuitenkaan aina ole mahdollista. Tämä vaikeuttaa hyvin toimivan sääntöjärjestelmän laadinnan. Musiikin tutkimuksessa tarvittaisiinkin lähestymistapaa, jota voidaan käyttää ilman eksplisiittisesti ilmaistua säännöstöä. Tällaisen lähestymistavan tarjoaa konnektionismi.

\section{Mitä on konnektionismi?}

Konnektionimismin perusajatus on, että suuri määrä itsenäisiä prosessointiyksiköitä, nk. keinotekoisia neuroneita, on kytketty toisiinsa ${ }^{5}$. Systeemissä oleva tieto on hajautetussa muodossa keinotekoisten neuroneitten välisinä kytkentöinä. Systeemi oppii siten, että syötteestä riippuen prosessointiyksiköiden välisiä yhteyksiä joko voimistetaan tai heikennetään. Hermoverkkoa voidaan opettaa antamalla syötteenä esimerkiksi kuvia tai ikoniseen muotoon koodattua ääntä. Verkon opettamisessa ei tarvita eksplisiittisesti formuloituja sääntöjä. Tämän vuoksi konnektionismi ja keinotekoisten hermoverkkojen käyttö on ollut suosittua niillä tutkimusaloilla, joilla sääntöjen muodostaminen on erityisen ongelmallista.

Konnektionistisilla systeemeillä on monia sellaisia ominaisuuksia, joita perinteisesti on pidetty tyypillisinä vain inmisille. $\mathrm{Ne}$ voivat $\mathrm{mm}$. täydentää epätäydellisiä kuviota, korjata virheellisiä kuvioita, oppia esimerkkien avulla, tuottaa uusia kuvioita aikaisemmin opittujen mallien perusteella ja yleistää. Esimerkiksi, jos hermoverkolle annetaan syötteenä epätäydellinen musiikillinen säe, systeemi kykenee täydentämään puuttuvat sävelet tai korjaamaan virheelliset.

\section{Toisintojen generointi}

Sundbergin ja Lindblomin tavoitteena oli laatia generatiivinen kielioppi, joka tuottaisi kansansävelmän Ro, ro till fiskeskär toisintoja ${ }^{6}$. Kieliopin säännöt laadittiin analysoimalla liitteessä 2 olevat Allan Mobergin keräämät toisinnot. Sääntöjärjestelmä tuotti liitteessä 3 näkyvät toisinnot. Tässä artikkelissa tavoitteenani on vertailla generatiivisen kieliopin ja hermoverkkojen käyttöä toisintojen tutkimuksen 
apuna. Esimerkkinä generatiivisesta lähestymistavasta käytän edellä mainittua Sundbergin ja Lindblomin tutkimusta. Keinotekoisten hermoverkkojen käyttöä tutkin kahdella verkkotyypillä: autoassosiaattorilla ja kuvioassosiaattorilla.

Alla olevassa kuvassa näkyy kuvioassosiaattori, johon on koodattu Ro, ro till fiskeskärin toisen toisinnon kaksi ensimmäistä säettä. $\mathrm{Ne}-$ liöt kuvaavat keinotekoisia neuroneita. Tummennetut neuronit ovat nk. aktivoituja neuroneita, jotka kuvaavat verkkoon koodattuja säveliä. Neuroniryhmien yksittäiset sarakkeet vastaavat kahdeksasosanuotin kestoisia säveliä. Neuroniryhmien rivit vastaavat sävelkorkeuksia.

Kuva 1. Kuvioassosiaattori, johon on koodattu yksi sävelmän Ro, ro till fiskeskär toisinnoista (ks. liite 2, toisinto 2).
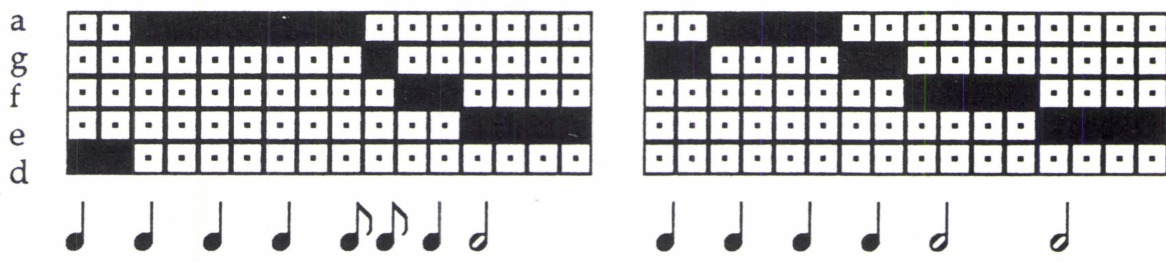

Opetin kuvioassosiaattorin liitteessä 2 nuottikuvaan *-merkillä osoitetuilla säepareilla. Autoassosiaattorin opetin syöttämällä samaan liitteeseen merkityillä säkeillä. Testasin molemmat assosiaattorit antamalla syötteeksi säkeen (kuvioassosiaattori) tai yhden tahdin (autoassosiaattori), joka muodostui opetettujen säkeiden osista. Liitteessä 2 on reunustettu ne assosiaattoreille opetettujen säkeiden osat, jotka syötteeseen on otettu mukaan. Samassa liitteessä näkyy myös muutama esimerkki siitä, mistä assosiaattoreille opetettujen säkeiden osista verkon vastaukset eli uudet toisinnot muodostuvat. Seuraavassa esimerkissä 1 näkyvät kuvioassosiaattorille ja autoassosiaattorille annetut syötteet ja assosiaattoreiden tuottamat toisinnot.

Molemmat assosiaattorit tuottivat uusia säkeitä eli säkeitä, joita ei sellaisenaan oltu opetettu verkoille. Lähempi tarkastelu osoittaa, että verkon tuottamat uudet säkeet muodostuvat opetettujen säkeiden osista. Verkot eivät ole käyttäneet säkeiden aineksia sellaisenaan, vaan ovat yhdistelleet oppimiensa säkeiden osasia "luovasti". Verkot käyttäytyvät näin ollen samaan tapaan kuin runonlaulajien sanotaan käyttäytyvän eli yhdistelevän oppimiaan formuloita uudella tavalla ja näin tuottavan jatkuvasti muuntuvaa musiikkia ${ }^{7}$. 


\section{Louhivuori}

Esimerkki 1. Assosiaattorien tuottamia vastauksia (uusia toisintoja) verkolle annettuun syötteeseen.

Kuvioassostaattort
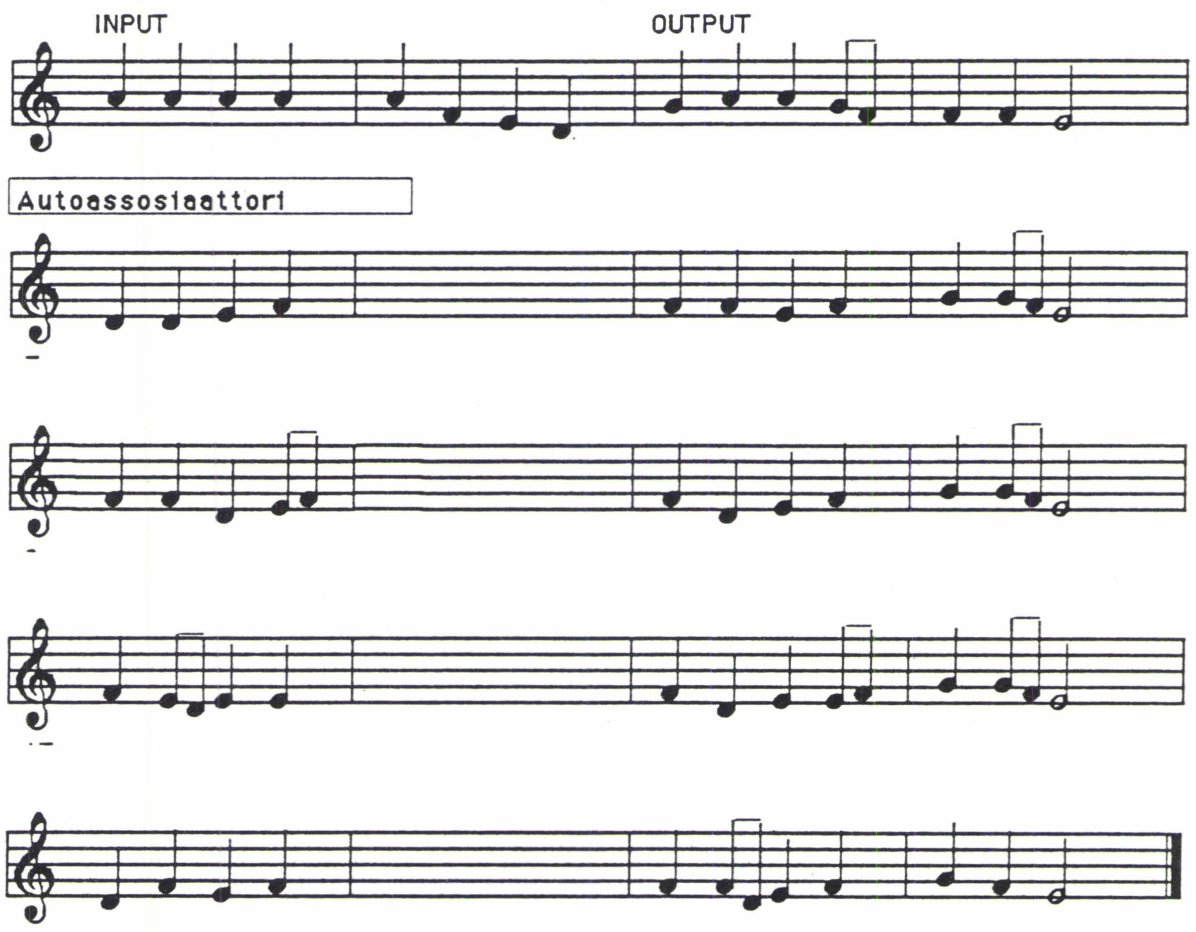

Verrattaessa verkkojen tuottamia toisintoja Sundbergin ja Lindblomin laatiman generatiivisen kieliopin tuottamiin toisintoihin, kiinnittyy huomio ainakin seuraaviin seikkoihin. Sundbergin ja Lindblomin generatiivisen kieliopin avulla toisintojen muotorakenne on helpompi hallita. Verkoissa muotorakenne voidaan esittää joko verkon rakenteen avulla tai implisiittisesti. Edellisessä vaihtoehdossa rakennettaisiin verkko siten, että kullekin rakenne-elementille laadittaisiin oma neuroniryhmä. Tällä menettelytavalla saataisiin todennäköisesti helposti kohtalaisen hyviä tuloksia. Vakavana puutteena olisi, että eri neuroniryhmissä olevien musiikillisten ideoitten välinen yhteys olisi hankala toteuttaa, jolloin eri neuroniryhmien välillä ei olisi "siirtovaikutusta". Vaikka tietty neuroninryhmä oppisi tietyn musiikillisen idean, se ei osaisi soveltaa oppimaansa ideaa muissa verkon neuroniryhmissä. Toinen ongelma liittyy neurofysiologiseen relevanssiin. Ainakaan tämän artikkelin kirjoittajalla ei ole tiedossa neurofysiologiaa koskevaa 
tutkimusta, joka viittaisi siihen, että aivot käsittelisivät musiikillisia rakenneyksiköitä, esimerkiksi säkeitä, erillään toisistaan. Musiikillisen muotorakenteen implisiittinen toteuttaminen perustuu siihen, että esimerkiksi kuvioassosiaattorissa verkko oppii assosiaation ja kontekstitietojen avulla mm. sen, missä järjestyksessä säkeet esiintyvät ${ }^{8}$.

Varsinaisen runonlaulun kannalta rakenteen hallintaan liittyvät verkkojen puutteet eivät ole ongelma, koska runonlaulu on yleensä rakenteeltaan selväpiirteistä. Sen sijaan tyylilajeissa, jossa rakenteet ovat monimutkaisempia, tämä keinotekoisiin hermoverkkoihin liittyvä ominaisuus on kysymys, joka vaatii jatkotutkimuksia ${ }^{9}$.

Sundbergin ja Lindblomin generatiivisen kieliopin tuottamille toisinnoille on tyypillistä, että melodiset ja rytmiset pääpiirteet ovat kohdallaan. Melodian ambitus on oikea, säkeet päättyvät asianmukaisesti ja nuottiarvot vastaavat mallina olleita toisintoja. Suurimmat puutteet löytyvät melodisista yksityiskohdista. Esimerkiksi toisinnossa n:o 3 toisen tahdin melodinen liike, jossa kahdeksasosanuotin kestoisen asävelen jälkeen tulee kvarttihyppy alaspäin tuntuu keinotekoiselta. Sama koskee toisinnon n:o 5 viidettä tahtia. Tosin on huomattava, että arviointi on subjektiivista. Kenties ruotsalaisille kuulijoille kyseiset melodiakuviot kuulostaisivat luontevilta? Tämän artikkelin kirjoittajan subjektiivisen mielipiteen mukaan assosiaattorien tuottamat toisinnot ovat lähempänä malleina toimineita toisintoja kuin generatiivisen kieliopin avulla laaditut.

Kieliopin ja verkon tulosten vertailua vaikeuttaa se, että verkon tuottamat toisinnot riippuvat oleellisesti toisaalta opetettujen säkeiden määrästä ja laadusta, ja toisaalta käytetystä syötteestä. Mitä lähempänä syöte on oppimisvaiheessa käytettyä aineistoa, sitä lähempänä verkon tuottamat toisinnot ovat malleja. Jos syötteenä käytetään vain vähän tai ei ollenkaan opetettuja säkeitä muistuttavia säkeitä, verkko tuottaa hyvin kaukana malleista olevia toisintoja. Myös verkolle opetettujen säkeiden määrä vaikuttaa sen käyttäytymiseen. Mikäli verkolle opetetaan monia toisiaan läheisesti muistuttavia säkeitä, verkolla on yhä suurempia vaikeuksia erotella niitä toisistaan. Tämähän on toisaalta hyvin inhimillinen piirre. Runonlaulussa tavattava runsas muuntelu voi johtua juuri tästä aivojen kapasiteettiin liittyvästä ominaisuudesta. Kun laulaja kuulee runsaasti toisiaan muistuttavia säkeitä, niiden tarkka muistaminen on myös aivoille vaikea tehtävä. 


\section{Päätteeksi}

Konnektionismi tarjoaa uuden ja lupaavan lähestymistavan toisintojen ja muuntelun tutkimiseen. Keinotekoisille hermoverkoilla näyttää olevan ominaisuuksia, joita on pitkään pidetty yksinomaan inmisille ominaisina, kuten kyky yleistää, oppia esimerkkien avulla ja tuottaa esimerkiksi uusia musiikillisia säkeitä ilman eksplikoituja sääntöjä. Jäljellä on kuitenkin monia vakavia kysymyksiä. Hermoverkot ovat edelleen kaukana inmisaivojen kapasiteetista ja ilmeisesti hermoverkot eivät edes arkkitehtuurinsa puolesta vastaa hyvin ihmisaivojen hermoston arkkitehtuuria. Joka tapauksessa keinotekoisten hermoverkkojen neurofysiologinen relevanssi on korkeampi kuin generatiivisessa lähestymistavassa, jossa tätä kysymystä ei edes vakavasti oteta huomioon ${ }^{10}$.

Konnektionismin yhteydessä nousee esille myös tieteenfilosofisesti tärkeitä kysymyksiä. On syytä pohtia, mikä metafora soveltuu parhaiten musiikin tutkimukseen. Tuoko aivometafora musiikin tutkimukseen jotain olennaista ja tärkeää, jota ei muilla lähestymistavoilla löydettäisi? Keinotekoisten hermoverkkojen tuotosten tulkinta on osoittautunut vaikeaksi. Näemme, että verkko käyttäytyy toivomustemme mukaisesti, mutta verkon elementaaristen informaation käsittely-yksiköiden, keinotekoisten neuronien hyvin monimutkaiset kytkennät vaikeuttavat sen selvittämistä, miksi verkko itse asiassa käyttäytyy niin kuin se käyttäytyy. Generatiivisen lähestymistavan etuna on, että tutkijan on eksplikoitava säännöt, johon kielioppi perustuu. Tämän ansiosta generatiivisen kieliopin toiminta voidaan hallita paremmin ja sen tuottamat tulokset ymmärtää paremmin. Ei pidä myöskään vähätellä sen tiedon määrää, joka saavutetaan sääntöjärjestelmän laadinnan yhteydessä. Konnektionismi ja erityisesti keinotekoiset hermoverkot antavat joka tapauksessa mahdollisuuden tutkia ilmiöitä, joita ei aikaisemmin ole ollut mahdollista tutkia esimerkiksi sen takia, että ei ole kyetty formuloimaan tarvittavaa säännöstöä. Musiikki ja muut taiteet sisältävät kysymyksiä, joiden tutkiminen on jätetty sivuun metodisten ongelmien vuoksi. Konnektionismi voi tarjota lähestymistavan, jonka avulla näitä kysymyksiä voidaan tutkia. Tämän lisäksi konnektionismi tarjoaa vanhoihin tutkimusongelmiin metodisesti uuden lähestymistavan. Tästä on hyvänä esimerkkinä toisintojen ja muuntelun tutkimus, joka tutkimusongelmana on lähes yhtä vanha kuin musiikkitiede itsenäisenä tieteenalana. 


\section{Lähteet}

Chomsky Noam (1957), Syntactic Structures. The Haque.

Eimas Peter D. and Galaburda Albert M. (edit.) (1990), Neurobiology of Cognition. Cambridge, Massachusetts.

Kaipainen Mauri (1990), Musiikin kuulemisen aivometafora. Musiikkitiede 1990:2, 3-28.

Lerdahl F. \& Jackendoff R. (1985), A Generative Theory of Tonal Music. London.

Leman Marc (1991), Symbolic and sub-symbolic descrition of music (käsikirjoitus, tullaan julkaisemaan lähteessä G. Haus (ed.), Music Processing, A-R Editions).

Lindblom Björn \& Sundberg Johan (1969), Towards a generative theory of melody. Svensk Tidskrift för Musikfroskning 52, 7188.

Lord Albert B. (1964), The Singer of Tales. Harvard Studies in Comparative Literature 24. Cambridge, Massachusetts.

Louhivuori Jukka (1992), Keinotekoiset hermoverkot ja sävelmätoisinnot. Kognitiivinen musiikkitiede (toim. Jukka Louhivuori ja Anu Sormunen). Jyväskylän yliopiston musiikkitieteen laitoksen julkaisusarja A: tutkielmia ja raportteja n:o 8, s. 169-189. Jyväskylä.

Shepherd Gordon M. (1990), The Significance of Real Neuron Architectures for Neural Network Simulations. Computational Neuroscience (editor Schwartz Eric L.) , 82-96.

Sundberg Johan (1972), Naturvetenskaplig metodik i musikforskning. Svensk Tidskrift för Musikforskning 7, 103-114.

Sundberg Johan \& Lindblom Björn (1976), Generative theories in language and music descriptions. Cognition 4. 99-122.

Sundberg Johan \& Lindblom Björn (1990), Generatiiviset teoriat kielen ja musiikin kuvailemisessa. Musiikin tutkimuksen rajoilla. Musiikintutkimuksen lähestymistapoja ja menetelmiä (toim. Jukka Louhivuori). Jyväskylän yliopiston musiikkitieteen laitoksen julkaisusarja A: tutkielmia ja raportteja 4, s. 3-30.

Schwartz Eric L. (ed.) (1990), Computational Neuroscience. Cambridge, Massachusetts. London.

Toiviainen Petri (1992), Keinotekoiset hermoverkot musiikin tutkimuksessa. Kognitiivinen musiikkitiede (toim. Jukka Louhivuori ja Anu Sormunen). Jyväskylän yliopiston musiikkitieteen laitoksen julkaisusarja A: tutkielmia ja raportteja n:o 8, s. 127-148. Jyväskylä. 


\section{Louhivuori}

Lite 1. Kaksi fraktaalia, jotka perustuvat samaan matemaattiseen kaavaan $\mathrm{zi}+1=\mathrm{zi} 2+\mathrm{c}$.
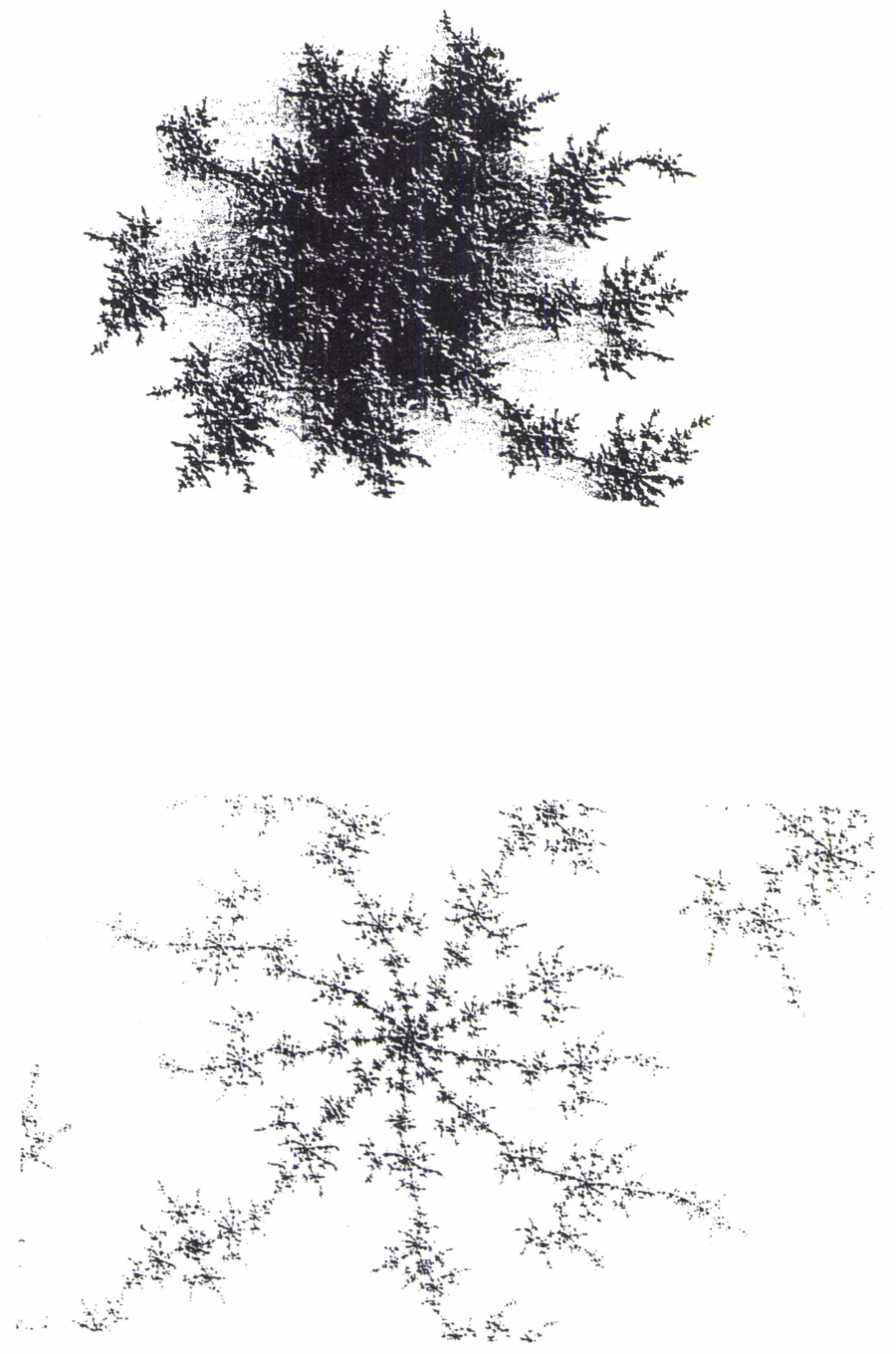
Liite 2. Allan Mobergin keräämiä toisintoja sävelmästä Ro, ro till fiskeskär. Nuottikuvassa on reunustettu syötteenä käytetyt säkeet tai niiden osat sekä verkon tuottamat uudet toisinnot.

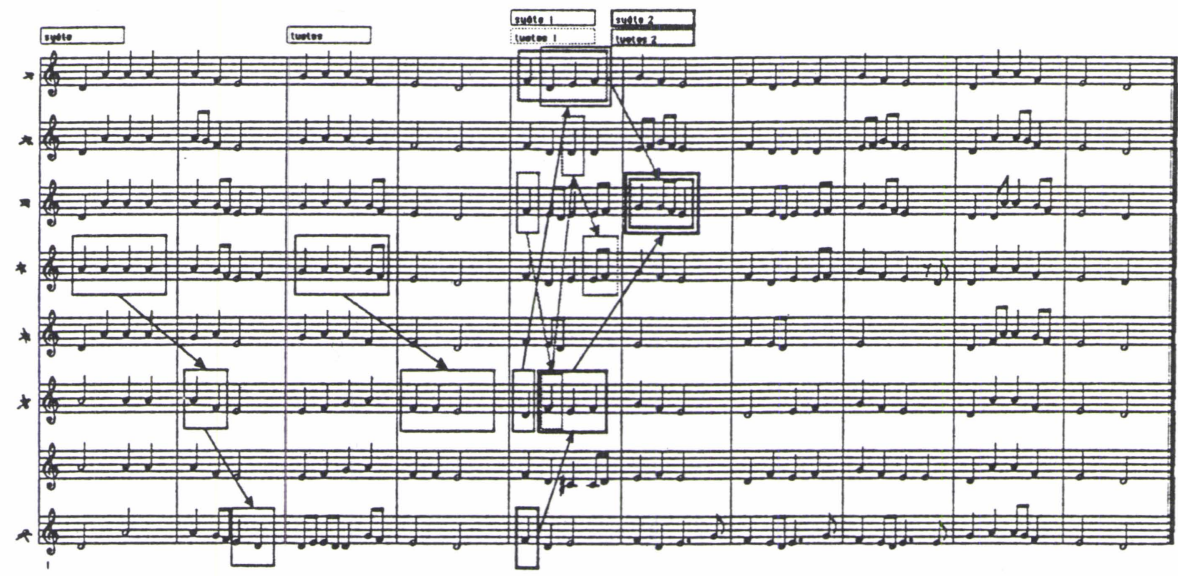

Lite 3. Sundbergin ja Lindblomin generatiivisen kieliopin tuottamia toisintoja.

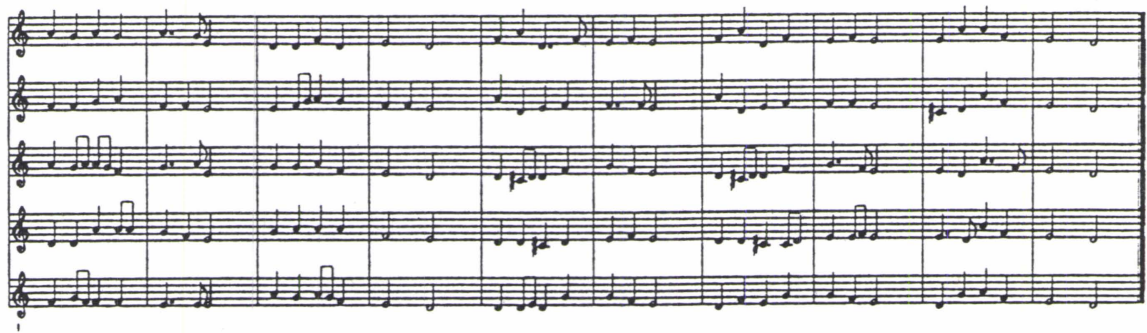

1 Chomsky 1957, Lerdahl \& Jackendoff 1985.

2 Lindblom ja Sundberg 1969, Sundberg 1972, Sundberg ja Lindblom 1976.

3 Fraktaalit on tuottanut Petri Toiviainen.

4 Leman 1991.

5 Tässä artikkelissa en käsittele tarkemmin konnektionismin perusteita, kuten konnektionististen hermoverkkojen laskennallista perustaa. Lisätietoja aiheesta saa mm. lähteistä Kaipainen 1990, Toiviainen 1992 ja Louhivuori 1992.

6 Sundberg ja Lindblom 1976, Ks. myös Sundberg ja Lindblom 1990.

7 Lord 1960, 17-22.

8 Tästä aiheesta on enemmän lähteessä Louhivuori 1992.

9 Ks. Toiviainen 1992.

10 Shepherd 1990, 82-96; Eimas ja Galaburda (ed.) 1990, 12. 